\title{
Young mentally handicapped adults in three London boroughs: prevalence and degree of disability
}

\author{
STEPHEN J. F. MITCHELL AND JULIE WOODTHORPE \\ From the Social Services Department, London Borough of Hounslow
}

SUMMARY A survey of 282 young adults, mentally handicapped on an administrative definition, was undertaken in the London Boroughs of Hounslow, Hammersmith, and Ealing between October 1978 and April 1980. The prevalence of mental handicap in the age group born between 1958 and 1963 was calculated, and variations were shown between the three boroughs and within the borough of Ealing. The findings suggested that the prevalence of severe mental handicap in this area is not markedly different from rates found in other British studies, but the administrative prevalence is inflated because numbers of mildly handicapped school leavers subsequently use the services for the mentally handicapped. Subjects were classified according to behavioural disabilities: young people in residential care were more likely to be severely incontinent, not literate, and without speech, but overall there was no relationship between degree of disability and placement in residential care.

Under the auspices of London borough/area health authority joint planning a survey of all mentally handicapped people born between 1 January 1958 and 31 December 1963, and the responsibility of Hounslow, Hammersmith, and Hounslow boroughs, was conducted in three stages. ${ }^{12} 3$ In this paper we draw together the findings on prevalence, disability, and the relationship between degree of disability and placement in residential care, from all three borough surveys.

\section{Method}

(1) Mental handicap has been described as 'an administrative concept, used for the purposes of social action'." An administrative definition of mental handicap was employed to include all 'severely' mentally handicapped people (that is, with IQ 50 or below) and the minority of 'mildly' handicapped people who use the services. The criteria for inclusion in the survey were that the person attended or had recently left a school for the educationally subnormal (severe) $(\operatorname{ESN}(\mathrm{S}))$ or an adult training centre, or lived in or had recently left a hospital or other specialised form of residential provision for the mentally handicapped, or received some other specialised service on the grounds of mental handicap, or was registered with the appropriate local authority social services department or health district as severely mentally handicapped. A total of 282 cases were identified.
(2) This definition enabled 'administrative prevalence's rates to be derived for age-specific populations, using Greater London Council projections of 1971 census data, and Ealing projections from a 1976 sample census. Application of an administrative definition inevitably leads to the inclusion of people who would not meet a scientific criterion of mental handicap, but who have used or currently use services for the mentally handicapped; thus prevalence rates may be influenced by the orientation of these services, the extent of provision for mildly handicapped people, and the climate of employment. Planning authorities are concerned with how many people need and use services, and it is in this sense that prevalence is used here.

(3) Wherever possible principal providers of care (parents and residential staff) were interviewed by one of the authors between October 1978 and April 1980 , using a specially developed schedule. If people in care had no contact with their parents care staff only were interviewed.

(4) No medical assessments were made of the nature or cause of the mental handicap. Parents were asked what they knew about the cause of handicap, and sometimes case records were made available to us. Both the methods had been used in other studies ${ }^{6}$ and their limitations are well known. The aetiological classification is used here merely to give context to the findings on disability which were the main focus 
of the survey. In the few cases where more than one aetiology was reported, that which seemed to be most relevant to the disability was coded.

(5) Information was collected using a schedule and scheme of analysis developed by the Wessex Health Care Evaluation Research Team. ${ }^{7}$ The schedule consists of 21 items rated on three-point scales, covering the areas of incontinence, mobility, self-help, literacy, speech, vision, hearing, and behaviour. The scheme of analysis derives six intermediate variables (mobility, incontinence, behaviour, literacy, speech, self-help). Two overall scales can then be derived: social and physical incapacity (SPI) and speech, self-help, and literacy (SSL). The logic of the analysis can be explained in flow chart form. ${ }^{8}$

\section{Results}

GENERAL CHARACTERISTICS

Of the 282 cases, $168(59.6 \%)$ were men and 114 $(40.4 \%)$ women. The mean age of the survey population at the time of interview was 18 years.

\section{AETIOLOGY}

The largest single group with known aetiology was formed by the 56 cases of Down's syndrome, 19.9\% of the total number of cases. Over half the cases (54.9\%) were of unestablished aetiology (Table 1).

Table 1 Classification of cases by aetiology

\begin{tabular}{|c|c|c|c|}
\hline & Aetiological factor & No. & $\%$ \\
\hline INFECTIVE & $\begin{array}{l}\text { TB meningitis } \\
\text { Meningitis } \\
\text { Maternal rubella } \\
\text { Postnatal infection }\end{array}$ & $\begin{array}{l}1 \\
7 \\
3 \\
1\end{array}$ & $\begin{array}{l}0 \cdot 4 \\
2 \cdot 5 \\
1 \cdot 1 \\
0 \cdot 4\end{array}$ \\
\hline TOXIC & $\begin{array}{l}\text { Maternal overdose } \\
\text { Postimmunisation }\end{array}$ & $\begin{array}{l}1 \\
4\end{array}$ & $\begin{array}{l}0.4 \\
1.4\end{array}$ \\
\hline INJURY & $\begin{array}{l}\text { Birth injury } \\
\text { Possible birth injury } \\
\text { Postnatal head injury }\end{array}$ & $\begin{array}{r}6 \\
14 \\
3\end{array}$ & $\begin{array}{l}2 \cdot 1 \\
5 \cdot 0 \\
1 \cdot 1\end{array}$ \\
\hline METABOLIC & $\begin{array}{l}\text { Hypercalcaemia } \\
\text { Phynylketonuria } \\
\text { Hypoglykemia }\end{array}$ & $\begin{array}{l}1 \\
2 \\
1\end{array}$ & $\begin{array}{l}0.4 \\
0.7 \\
0.4\end{array}$ \\
\hline MALFORMATION & $\begin{array}{l}\text { Down's syndrome } \\
\text { Microcephaly } \\
\text { Hydrocephaly } \\
\text { Cerebral palsy } \\
\text { Hydrocephaly and spina bifida } \\
\text { Sturge Weber syndrome } \\
\text { Helleman-Streife syndrome } \\
\text { Mixed diagnoses } \\
\text { Other malformation }\end{array}$ & $\begin{array}{r}56 \\
5 \\
5 \\
12 \\
1 \\
1 \\
1 \\
2 \\
2\end{array}$ & $\begin{array}{r}19 . \\
1.8 \\
1.8 \\
4 \cdot 3 \\
0.4 \\
0.4 \\
0.4 \\
0 \cdot 7 \\
0.7\end{array}$ \\
\hline UNKNOWN CAUSE & $\begin{array}{l}\text { Motor disturbance } \\
\text { Epilepsy } \\
\text { No neurological signs } \\
\text { Autism }\end{array}$ & $\begin{array}{r}3 \\
41 \\
103 \\
6\end{array}$ & $\begin{array}{r}1 \cdot 1 \\
14 \cdot 5 \\
37 \cdot 2 \\
2 \cdot 1\end{array}$ \\
\hline ALL CASES & & 282 & $100 \cdot 0$ \\
\hline
\end{tabular}

\section{PREVALENCE}

The overall prevalence rate (age group approximately $15-20$ ) was 5.02 in 1000 (Table 2). The highest prevalence rate was in Hammersmith (5.92), with a lower rate in Hounslow (5.3), and the lowest rate in Ealing (4.2). If the survey had been restricted to people principally educated at $\operatorname{ESN}(\mathrm{S})$ schools, or mental handicap hospital schools, or excluded from education, the overall number of cases would have been 201 , and the overall prevalence 3.58 in 1000 .

Table 2 shows considerable variations in prevalence between the three boroughs. The more detailed population figures available for the borough of Ealing revealed considerable variations within this borough: prevalence in the 24 wards ranged from 13.16 to 0.0 in 1000 in the age group studied.

Before the project was undertaken there was some local concern that the numbers of mentally handicapped people in Ealing's large immigrant Asian population were larger than would be expected from national rates. ${ }^{9}$ No evidence was found for this in the age group studied: the ward with the highest immigrant Asian population (Northcote, 78\% Asian) had a low prevalence rate of 1.6 in 1000 . The ward with the highest prevalence (Mount Pleasant, 13.16 in 1000 ) had a mixed population (24\% Asian, $5 \%$ West Indian).

\section{DISABILITY FINDINGS}

Disability data are essential to illustrate the range and extent of dependence which must be catered for in planning community support, day, and residential services. Complete data were obtained for 279 cases.

(1) The great majority of young mentally handicapped people had no problems of incontinence. But wetting at night was a problem in over a quarter of the cases and a sizable minority $(12 \%)$ were constantly doubly incontinent.

(2) Non-ambulance, which is defined by the Wessex Health Care Evaluation Research Team as unable to walk on the flat even with help, was total for 19 young people, and just under $10 \%$ could not walk at all by themselves.

Table 2 Prevalence in the three boroughs and overall (1958-63 age group)

\begin{tabular}{llcl}
\hline BOROUGH & $\begin{array}{l}\text { POPULATION } \\
\text { (age-specific)* }\end{array}$ & $\begin{array}{l}\text { CASES } \\
\text { (number) }\end{array}$ & $\begin{array}{l}\text { PREVALENCE } \\
\text { (in 1000) }\end{array}$ \\
\hline Hounslow & 18600 & 99 & $5 \cdot 30$ \\
Hammersmith & 14700 & 87 & $5 \cdot 92$ \\
Ealing & 22840 & 96 & 4.20 \\
OVERALL & 56140 & 282 & 5.02 \\
\hline
\end{tabular}

* Population estimated for Hounslow and Hammersmith derived from Greater London Council projection from 1971 census data.

Population estimate for Ealing derived from London Borough of Ealing projection and from 1976 sample census. 
(3) No assistance with feeding or special preparation of food was required for $80 \%$ of the young people, but less than half were able to wash and dress without any help. Twenty-seven per cent needed to be washed completely and $21 \%$ to be dressed completely.

(4) Problems of communication contribute significantly to handicap, reducing the quality and effectiveness of a person's interaction. Twenty-two per cent could not speak at all and a further $20 \%$ only said odd words. Of the 159 who could hold a conversation, a quarter were difficult to understand because of speech impediments.

Table 3 Summary disability variables by place of residence

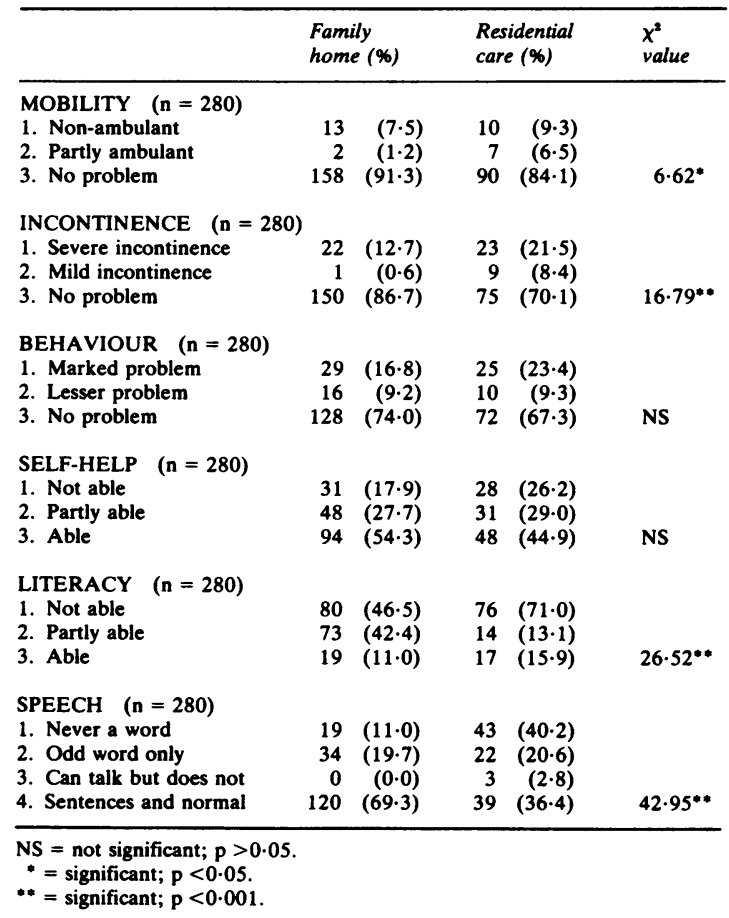

(5) As expected in a population of mentally handicapped people, formal skills in reading, writing, and counting were generally low. Half the young people could not recognise or write their own names, and $44 \%$ could make no effective use of counting. Between $13 \%$ and $21 \%$ could read a simple book, or write a short letter, or count money, or do two or all three of these things.

(6) Although clinical examinations of hearing and vision might reveal more impairments, $85 \%$ had no reported defects of vision (not remediable by spectacles) and $90 \%$ had no reported defects of hearing. Fifteen people were blind and 12 deaf.

(7) On each of the five behaviour problems on the schedule over three-quarters of the survey population were rated as 'no problem'. The least prevalent problem was self-injury (14\%). Each of the other problems (aggressiveness, destructiveness, over-activity, constantly seeking attention) were rated for just over $20 \%$ of the cases.

\section{DISABILITY SCALES}

By deriving summary variables for mobility, incontinence, behaviour, self-help, and literacy (Table 3) two overall scales (SPI and SSL) can be produced (Table 4). The 'mild incapacity' and 'no incapacity' categories of the SPI scale can be grouped as CAN (continent, ambulant, no severe behaviour disorder), and cases in the other four categories as CAN'T. In this survey of young adults $70 \%$ of the cases were CAN and 30\% CAN'T.

Table 4 cross-tabulates SPI by SSL scores and shows that the two scales are significantly related. This is more true at the lower than the higher level of the ability spectrum; all 35 people in the lowest two categories of SPI were also in the lowest two categories of SSL. People with higher ratings on the SPI scale were much more widely distributed on the SSL scale. And 17 cases rated in the literate and self-help/speech categories of SSL were in the CAN'T group of SPI because of disturbed behaviour.

Table 4 Social and physical incapacity by speech, self-help, and literacy

\begin{tabular}{|c|c|c|c|c|c|c|c|}
\hline \multirow[b]{2}{*}{$S P I$} & \multicolumn{7}{|l|}{$S S L$} \\
\hline & No $S S L$ & Speech & Self-help & $\begin{array}{l}\text { Self-help } \\
\text { and speech }\end{array}$ & Literate & TOTAL & $(\%)$ \\
\hline Non-ambulant & 20 & 3 & 0 & $\mathbf{0}$ & $\mathbf{0}$ & 23 & $(8 \cdot 2)$ \\
\hline Ambulant, severe behaviour disorder, incontinent & 15 & $\mathbf{0}$ & 0 & 0 & 0 & 115 & $(5 \cdot 3)$ \\
\hline Ambulant, severe behaviour disorder & 11 & 2 & 6 & 9 & 8 & 36 & (12.9) \\
\hline Ambulant, incontinent & 6 & 3 & 0 & 1 & $\mathbf{0}$ & 10 & $(3.5)$ \\
\hline Mild incapacity & 16 & 5 & 1 & 4 & 3 & 29 & $(10 \cdot 3)$ \\
\hline No incapacity & 26 & 26 & 17 & 72 & 25 & 166 & (59.4) \\
\hline TOTAL (\%) & $94(33 \cdot 6)$ & $39(13.9)$ & $24(8 \cdot 6)$ & $86(30 \cdot 8)$ & $36(12 \cdot 9)$ & 279 & $(100)$ \\
\hline
\end{tabular}

Raw $\chi^{2}=109.77 ; 20 \mathrm{df}$.

$\mathrm{p}<0.001$. 
Table 5 Disability scales (SPI and SSL) by place of residence

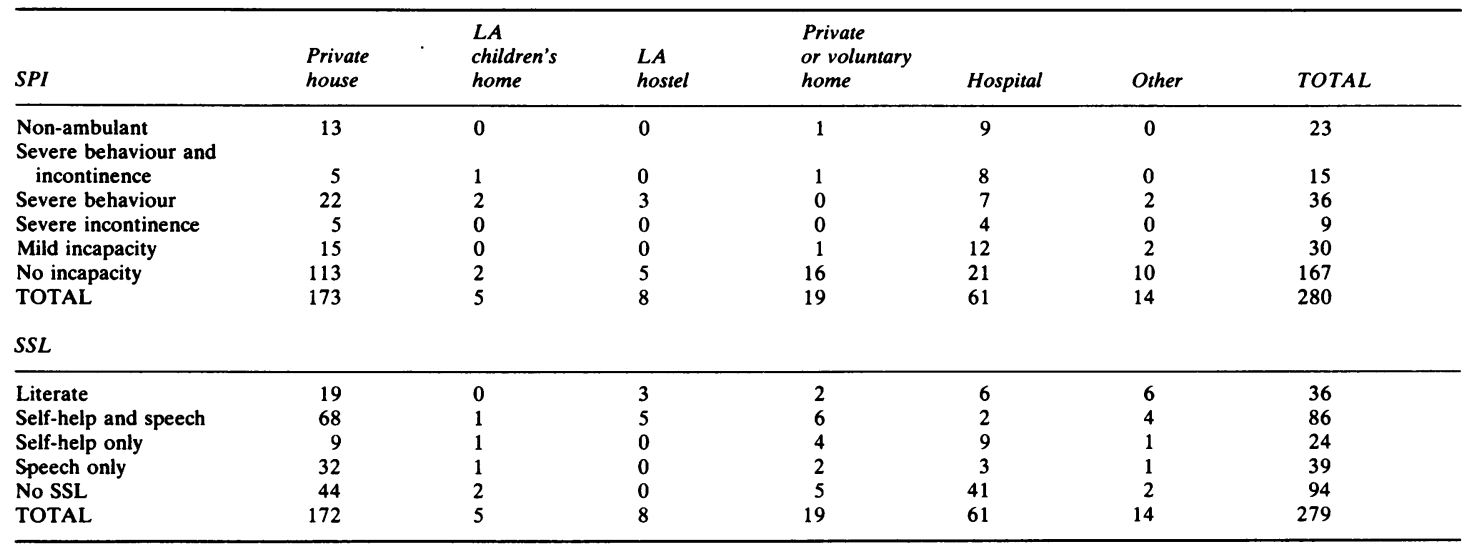

RELATIONSHIP BETWEEN DISABILITY AND PLACE OF RESIDENCE

Overall, $62 \%$ of the young people were living with their families, and $38 \%$ were in some form of residential care. Of 108 people in residential care, $57 \%$ were in hospitals for the mentally handicapped (Table 5).

Table 5 cross-tabulates scores on the SPI scale with place of residence and there is no evidence of a clear relationship. More of the most dependent people (non-ambulant, doubly incontinent) were living in family homes than in residential care. It was only in the category of severe behaviour disorder and severe incontinence that more people were in residential care than living with their families. At the other end of the scale, a third of those rated as 'no incapacity' were in residential care, including 21 people in hospitals for the mentally handicapped.

To test the relationship statistically, the component variables of the SPI scale were all cross-tabulated with place of residence. Using a $\chi^{2}$ test, no significant relationship was found between disturbed behaviour and placement in residential care. Incontinence was significantly more prevalent in the residential care group $(21 \%$ severely incontinent compared with $13 \%$ ). Impaired mobility was also more prevalent in the residential care group $(16 \%: 9 \%)$, although the proportions of non-ambulant people at home and in residential care were similar. Overall, there was no significant difference between the proportions of CAN and CAN'T cases at home and in residential care (Table 6).

Examination of the component variables of the SSL scale (Table 3) shows that the presence or absence of self-help skills was not related to residential placements. There were more 'literate' people, proportionately, in the residential care group
Table 6 Social and physical incapacity (SPI) by place of residence (collapsed)

\begin{tabular}{lrllr}
\hline & Family home (\%) & Residential care (\%) & TOTAL \\
\hline SPI & & & & \\
CAN'T & 46 & $(26 \cdot 6)$ & $38(35 \cdot 5)$ & 84 \\
CAN & $127(73 \cdot 4)$ & $69(64 \cdot 5)$ & 196 \\
TOTAL & $173(100 \cdot 0)$ & $107(100 \cdot 0)$ & 280 \\
\hline
\end{tabular}

Corrected $x^{2}=2 \cdot 1 ; 1 \mathrm{df}$

NS: $\mathbf{p}>\mathbf{0} \cdot \mathbf{1}$.

than the family home group (15\% to $11 \%)$, but the difference was more significant for those with no skills in reading, writing, and counting: $71 \%$ of the residential care group and $46 \%$ of the family home group. The residential care group were significantly more impaired in speech: overall, $32 \%$ of those whose communication was rated as 'sentences and normal' were in residential care, compared with $56 \%$ of those whose speech was non-existent or severely limited. Absence of speech was usually associated either with profound handicap, or with defects of vision and hearing or disturbed behaviour, or both.

\section{Discussion}

\section{PREVALENCE}

A previous study in west London ${ }^{10}$ used an IQ below 50 as a criterion for inclusion of cases: the prevalence rate was 3.45 in 1000 for children aged 7-14, and 3.61 for children aged 10-14. A similar study in Camberwell $^{11}$ found a prevalence rate of 3.89 in 1000 at ages 5-14. A follow-up study in Camberwell $^{12}$ included children with IQ less than 50 'plus a few children whose educational and social limitations are so severe that, even if they do score 50 or more on some tests, they are still catered for by schools or other units intended for severely retarded children'. The prevalence rate derived from this 
broader definition was 4.3 in 1000 at ages $0-14$. A survey in Sheffield ${ }^{13}$ did not use IQ scores, but an administrative criterion of attendance at $\operatorname{ESN}(S)$ schools or mental handicap hospital schools; this derived a prevalence rate of 3.8 in 1000 at ages 12-16. Kushlick gives findings for psychometrically based studies in Salford (1961) and Wessex (1963), of a similar age group to that studied here, with prevalence rates of 3.54 to 3.84 in 1000 at ages $15-19 .^{14}$

The rates found in this survey $(5.02$ in 1000 aged $15-20 ; 3.58$ in 1000 using a more restricted definition) suggest that the prevalence of severe mental handicap in Hounslow, Hammersmith, and Ealing is not markedly different from rates found in other British studies. But the administrative prevalence among young adults is inflated because between 1.0 and 1.5 in 1000 of the population make use of services for the mentally handicapped when they leave school, although they are only midly handicapped. In the current climate of employment, it will be increasingly hard for those leaving schools for the educationally subnormal (medium) (ESN(M) to obtain jobs, and this trend in prevalence rates is likely to continue.

A study of the distribution of the mentally handicapped between districts of Sheffield found wide variations in referral rates to a case register from different postal districts within the city. ${ }^{15}$ The author concludes:

If there are ever to be properly planned community based services for the mentally handicapped, planning authorities at all levels will have to recognise that averages and norms are at best misleading, and at worst, restrict progress.

Different areas, even within the same city, must be expected to differ in their needs and demands for mental handicap services and the existing and future services ought to be organised and run to reflect these differences.

The study reported here found variations in prevalence between the three boroughs ranging from 5.9 in 1000 in Hammersmith to 4.2 in Ealing. There were also considerable variations within the borough of Ealing. It seems clear that the local planning of services should be based on local prevalence data.

\section{IS A B I LITY}

The findings of disability studies vary according to the methods used and the age groups studied. The overall findings of this survey on disability are very similar to those of a Wessex survey of young people aged 15-19, which employed the same methods, in 1963. ${ }^{14}$ The Wessex findings were $73 \%$ CAN and $27 \%$ CAN'T, including $7 \cdot 9 \%$ non-ambulant. In this study $70 \%$ were found to be CAN and $30 \%$ were CAN'T, including $8 \cdot 2 \%$ non-ambulant.
RELATIONSHIP BETWEEN DISABILITY AND PLACE OF RESIDENCE

A number of British studies have identified the severity of the individual's physical and mental handicap as a key determinant of need for residential care. A study in London in 1961 found that $62 \%$ of an institutionalised sample had social ages of under 3 compared with $25 \%$ of a sample in family homes. ${ }^{16}$ A study in north-east Scotland in the early 1970 s found that of 3020 individuals studied, $35.4 \%$ were in residential care. But $70 \%$ of those with IQ less than 20 were in residential care, compared with $46 \%$ of those with IQ $20-50$, and $22 \%$ of those with IQ over 50. The authors concluded that 'it would appear that the type of care received by any handicapped individual is dependent on a complex of factors with availability of service, grade of handicap, and age being perhaps most relevant' ${ }^{17}$

Two studies using the same disability scales employed here also found significant relationships. That in Wessex in 1963 found a rate for CAN'T children in residential care of 14 in 100000 compared with 6 in $100000 \mathrm{CAN}$ children, although overall there were far more CAN than CAN'T children in the population studied. ${ }^{14}$ They did, however, conclude that there was almost one CAN'T child at home for every one in an institution, and that the proportion of CAN people in institutions was considerable, particularly among adults. The other study, in Sheffield in 1975, found that there were more heavily dependent children at home than in hospital but 'a significantly greater proportion of children who were in residential care were either non-ambulant or severely incontinent or had a severe behaviour disorder', and the author concluded that

in 1975 there was a high correlation of severity of mental handicap with admission to long-term residential care, presumably caused by the shortage of available places which prevented admissions of less severely handicapped children for whom residential care may be beneficial for social or other reasons. ${ }^{13}$

In contrast to these findings, no significant relationship was established in this study between degree of disability, measured on the SPI scale, and placement in residential care. One significant relationship established was between lack of effective speech and placement in residential care. This is similar to the findings of a survey in Camberwell in 1972: the author concluded that while the absence of language in a profoundly handicapped young person with an IQ of under 20 is predictable 'those with non-verbal IQs of 20 and above, with no language, present a special problem, as is shown by the correlation of language impairment with defects of hearing and vision, disturbed behaviour and admission to residential care, independently of the 
non-verbal IQ level'. ${ }^{12}$ Considering that the young people without effective use of speech included the most profoundly physically disabled and some of the most disturbed and disruptive cases in our survey, it is not surprising that $53 \%$ of those cases were in residential care. Because many heavily dependent or severely disruptive young adults continue to live at home with their families, considerable pressure is put upon day services: $10 \%$ of the survey population had no organised day placements or activities. The survey also highlights the lack of local residential alternatives in Hounslow, Hammersmith, and Ealing. The three boroughs have no homes for non-ambulant mentally handicapped children, and no homes for mentally handicapped adults who are incontinent, non-ambulant, or have severe behaviour disorders. The area health authority has no residential facilities for the mentally handicapped within the area.

We thank all parents who agreed to be interviewed and all professionals employed in the field of mental handicap in Ealing, Hammersmith, and Hounslow. We also thank the Director of Social Services, London Borough of Hounslow, in whose department we were employed for the duration of this project. The project was jointly funded by Ealing, Hammersmith, and Hounslow Area Health Authority (Teaching).

Reprints from Mr. S. J. F. Mitchell, Senior Research Officer, Social Services Department, Borough of Hammersmith, Hammersmith Town Hall, King Street, London W6.

\section{References}

${ }^{1}$ Mitchell SJF, Woodthorpe J. A survey of young mentally handicapped people in the London Borough of Hounslow. London: London Borough of Hounslow, 1979.
${ }^{2}$ Mitchell SJF, Woodthorpe J. A survey of young mentally handicapped people in the London Borough of Hammersmith and Fulham. London: London Borough of Hounslow, 1980.

${ }^{3}$ Mitchell SJF, Woodthorpe J. A survey of young mentally handicapped people in the London Borough of Ealing. London: London Borough of Hounslow, 1980.

${ }^{4}$ Clarke AM, Clarke ADB. Criteria and classification of subnormality. In: Clarke AM, Clarke ADB, ed. Readings from Mental Deficiency. The changing outlook. London: Methuen, 1978: 18-25.

${ }^{5}$ Tizard J. Community services for the mentally handicapped. London: Oxford University Press, 1964.

${ }^{6}$ Weale J, Bradshaw J. Prevalence and characteristics of disabled children: findings from the 1974 General Household Survey. J Epidemiol Community Health 1980; 34: 111-8.

${ }^{7}$ Kushlick A, Blunden R, Cox GR. A method of rating behaviour characteristics for use in large-scale surveys of mental handicap. Psychol Med 1973; 3: 466-78.

${ }^{8}$ Dawes B. A method of rating behaviour characteristics: Flow Chart of Classification Procedure. Health Care Evaluation Research Team, Research Report No. 139. Winchester: Wessex Regional Health Authority, 1977.

${ }^{9}$ Department of Health and Social Security. Better Services for the Mentally Handicapped. London: HMSO, 1971.

${ }^{10} \mathrm{Goodman}$ N, Tizard J. Prevalence of imbecility and idiocy among children. $\mathrm{Br} M e d \mathrm{~J}$ 1962; i: 216-9.

${ }^{11}$ Wing L. Severely retarded children in a London area: prevalence and provision of services. Psychol Med 1971; 1: 405-15.

${ }^{12}$ Gould J. Language development and non-verbal skills in severely mentally retarded children: an epidemiological study. Ment Defic Res 1976; 20: 129.

${ }^{13}$ Martindale A. Severely subnormal children from Sheffield Metropolitan District between 12 and 15 years of age on 31 July 1975. Sheffield: Sheffield Area Health Authority, 1975.

${ }^{14}$ Kushlick A, Cox GR. The epidemiology of mental handicap. Dev Med Child Neurol 1973; 15: 748-59.

${ }^{15}$ Martindale A. The distribution of the mentally handicapped between districts of Sheffield. Sheffield: Sheffield Area Health Authority (Development Project), 1979.

${ }^{16}$ Tizard J, Grad JC. Mentally Handicapped Children and their Families. London: Oxford University Press, 1961.

${ }^{17}$ Scottish Home and Health Department. Mental Subnormality in North East Scotland. A Multi-Disciplinary Study of Total Population. Edinburgh: HMSO, 1978. 